\title{
Issues associated with energy efficiency programs implementation at the housing and utility enterprises
}

\author{
Natalia Borisova ${ }^{1, *}$, Alexander Borisov ${ }^{2}$, and Natalia Fedonuk ${ }^{1}$ \\ ${ }^{1}$ The department of management and urban development and construction, Volgograd State Technical University, Volgograd, \\ Russia \\ ${ }^{2}$ The department of economics and management of construction projects, Volgograd State Technical University, Volgograd, \\ Russia
}

\begin{abstract}
Energy saving potential is quite huge in the most sectors of the national economy, particularly in housing and utilities and industry. Due to this, energy efficiency increase at the enterprises of housing and utilities and industry through the energy efficiency programs implementation, is one of the priorities in the modern economy of Russia and its regions, and requires radical measures to improve the effectiveness of its implementation. The purpose of the authors is the scientific and practical study of the main problems of energy efficiency programs implementation at the enterprises of housing and utilities services and industry in modern conditions. To achieve this purpose the authors solved the following problems: the current state of the housing and utilities sector and industry, the relevance and the need for energy saving policy at the enterprises of housing and utilities services and industry are studied; the main problems impeding to implement the energy-saving program effectively at the enterprises of housing and utilities services and industry are determined; the possible ways of solving the problems identified in the energy efficiency programs implementation at the enterprises of housing and industry are offered. The team of authors focuses in this study on the problems of the energy audit using in practice as a basic tool for the energy saving programs development at the enterprises of housing and utilities services, industry and their subsequent implementation. The subject of author's researches is the factors that determine the energy efficiency programs implementation at the enterprises of housing and utilities services and industry at the level of individual region and the whole country, and the object is the enterprises of housing and utilities services and industry. Methodologically the scientific and practical research is based on the complex approach using the methods of comparative, statistical and logical analysis.
\end{abstract}

\section{Introduction}

The main motive is undoubtedly a factor of energy resources exhaustion for saving energy. The idea of energy saving appeared in the late 20th century during the global energy crisis, when most of the advanced countries of the world has sought to improve the efficiency of existing energy sources and to use new alternative and renewable sources $[8 ; 11 ; 13 ; 14 ; 21 ; 23$; $25 ; 26]$.

In the new economic conditions, and for many years the energy saving is a fundamental factor in the effective functioning and perspective development of the most enterprises in the housing and utilities services, the industry of many leading countries, especially Russia [7; $9 ; 10 ; 15 ; 19 ; 20 ; 24]$. The practical realization of energysaving potential is the high priority of the federal and regional economic policy in Russia, as in the new economic conditions, each percentage of fuel-energy resources saving used in production and economic activity of the national economy enterprises can provide the national income increase more than $0.35 \%[1 ; 4]$. The main purpose of energy saving policy in the housing and utilities sector and industry is to reduce the cost price of services and goods manufactured in these spheres.

\section{Relevance and research of the problem situation}

Currently, Russia is the energy surplus country, but the situation is getting worse every year, and therefore, the energy crisis can come, if the measures are not applied in the using of the existing energy saving potential in our country. In 2014, energy intensity has undergone a decline of $5.61 \%$ compared to 2007 . Despite the positive trend, without the implementation of a competent energy saving policy it is difficult to achieve the result set by the President of the Russian Federation and in the "country's

* Corresponding author: borisovani06@mail.ru 
energy strategy until 2020" (reduction of the GDP energy intensity by $40 \%$ ) [3; 6]. Priority ways of energysaving policy are the industrial sector of the economy, agriculture, construction industry and housing and utilities services. Thus the greatest losses of fuel-energy resources are observed in the industrial (47\%), construction industry $(22 \%)$, as well as housing and utilities services and agriculture $(28 \%)$ in Russia and its regions in modern conditions $[4 ; 6]$.

These sectors are interrelated, but especially the housing and utilities sphere unites each of them. For example, any industry can be either the supplier or the customer or the end service user. It was found that only the residential and industrial buildings consume more than $70 \%$ of electricity, $49.8 \%$ of natural gas, $40 \%$ of fossil energy resources. Therefore, the rational use of energy in housing and utilities sector and in the industry is one of the priority tasks in the sphere of energy saving $[5 ; 19 ; 26 ; 27]$.

The energy saving reserves are most huge in heating in large and small Russian towns. The main reasons for this are, firstly, the huge scale of this scope (for heat generation in the northern regions of Russia more than $150 \mathrm{mln}$. standard fuel is spent per year), and, secondly, the absence of starting base for the implementation of energy saving arrangements. As a result, it is impossible to perform effectively the accounting and control produced, transmitted and consumed by thermal energy. It should also be noted that in the majority of Russia regions the morally and physically obsolete technical equipment is used in heating systems, especially in the transport of heat, which have been developed over 50 years ago.

Energy losses in distribution (often working with flooding) heating networks and in local heat systems of small objects in utilities sphere are characterized by its scale. Water treatment systems are not effective enough in small local boiler rooms, this leads to the formation of scum in boilers and heat exchangers and to a consequence of this reduction in their efficiency. When the scum overgrow in boilers working in hot water systems, boiler efficiency decreases to $60 \%$ after $2-3$ months exploitation in conditions of bad water using [1; 2].

Analysis of water and sewer networks characteristics, realized by the Russian Association of Water Supply and Sanitation, showed that the average percentage of water supply systems depreciation (in 70 Water Channels) is $75 \%$, sewerage $-70 \%$, newly constructed, reconstructed and shifted water networks in recent years, is near $0.72 \%$, sewerage $-0.44 \%$ of the total length of all networks. If you take annual standardized percentage of about $5 \%$ to restore the water supply network, underdone repair of water networks in the past few years will exceed more than $21 \%$, and sewerage networks - more than $22 \%$ [2; 3$]$.

Thus, water and sewage networks operating costs increase and unaccounted costs of water resources reach up to $30 \%$ in the large and small cities and towns of our country. The number of accidents is also increasing. Water losses of our country are more than $23 \%$ per year as a result of the enormous physical and moral depreciation of fixed assets in water supply and sewage enterprises, in some cities the losses of water reached $40 \%$. In addition, the accident rate of water supply and sewerage networks reaches until 6 accidents per $1 \mathrm{~km}$ of network per year. The physical and moral deterioration of networks and facilities of water supply and sanitation sector have reached more than $80 \%$ in some regions (according to the Ministry of Regional Development). As a result, more than $42 \%$ of water supply networks shall be changed, sewerage networks - more than $35 \%$ of the total stretch. However, it should be noted that less than $1.5 \%$ water and $0.5 \%$ sewerage networks is chanced each year $[3 ; 27]$.

Also, it is important to note that a large number of various types of energy losses in the housing and utilities sector and industry is due to the negligent attitude to the consumption of energy resources by consumers. Through the windows and doors of residential and industrial buildings more than $70 \%$ of heat is lost. Very often in our homes and industrial buildings, a heating equipment works at full power, but because of the lack of modern heat regulation systems, consumers need to air their residential and industrial rooms, thereby creating a direct energy losses. As a result, Russia's extravagance, the neglect of the energy, heat, water consumption, energy efficiency of housing and utilities services sector and industry in Russia is 5 times lower than in Europe $[2 ; 3]$.

Undoubtedly, we are confident that the energy efficiency of each residential and industrial object depends primarily from the consumer. If we, the consumers, want to pay bills according to real indexes of energy, heat consumption, but not the losses inheriting in tariffs, it is necessary to demand installation of energy saving systems with suppliers, intermediaries of utilities services (e.g. installation of water gas, electricity counters, etc., as well as regulators of heat supply).

Such huge savings potential and the annual increase of energy, heat and water cost, made a very topical problem of energy saving for the enterprises of housing and utilities sector and industry in the majority of Russia regions.

\section{The research and statement of the realisation problem of energy saving program}

One of the ways to solve the above problems in 2000 was the creation of the subprogram "Energy supply saving in housing and utilities services", "Energy efficiency in energy-intensive industries," of the federal program "Energy saving in Russia" for practical implementation. Every town should have developed the energy supply saving programs in housing and utilities sector and energy efficiency in the industry, including specific arrangements to save energy, water and heat resources with the technical and economic assessment of the required costs and expected economic effect. The main tool for the development of energy-saving programs, and their subsequent implementation in practice is an energy audit of different objects which 
belong to the enterprises of housing and utilities services and industry. Energy audit includes energy research of these objects, as well as an analysis of possible savings reserves and technical and economic efficiency account of the developed energy-saving arrangements.

Typically, energy audit is a comprehensive analysis of all residential and non-residential objects, belonging to the legal entity. Also the current state of the engineering infrastructure of each customer's object is investigated. In other words, all the factors are investigated and identified that contribute to energy, heat and water loss, which in turn leads to overruns of above mentioned resources and to overpayment for their use.

According to the results of surveys $g$ energy certificate is formed, containing all the parameters of the investigated companies, and some recommendations can also be given to use the specific energy-saving technologies, taking into account the specifics of the production activities of the studied enterprise [6].

Since the release and adoption of subprograms "Energy supply saving in housing and utilities services", "Energy saving in energy-intensive industries" more than 10 years have passed, but massive development did not happen at the regional and municipal level of these subprograms.

As the leading energy audit experts, not all heads of regional enterprises of housing and utilities sector and industry aware of the need for energy survey and energy audit of their businesses. Most of the heads of regional enterprises of housing and utilities sector and industry do not think, ignore the real possibility of saving its heat, energy resources. It should be noted that this is extra cost, extra actions for many managers. In addition, energy losses are profitable for some regional enterprises of housing and utilities complex, as their value is on the maxim laid in the tariffs of utilities services

As a result of inactivity of the majority enterprises of utilities sector and industry, the Federal Law № 261-FL has been developed and enacted at regional and municipal level in the sphere of energy saving "About energy saving and energy efficiency increase and about changes in certain legislative acts of the Russian Federation". In accordance with this Federal Law the list of enterprises was approved, which necessarily had to undergo energy audits until 31 December 2012. Also this list includes the organizations such as: public authorities and local self-government, with rights of legal entities; organization with the participation of the state or municipality; organizations, the overall cost of which are more than $10 \mathrm{mln}$. rub. per year for all kinds of fuel, fuel oil, heat, coal, electric power consumption $[3 ; 18]$.

However, the enactment of the law has caused a lot of questions from leading economists and market experts of energy audit and energy services. Most of the leading energy audit experts believe that the Federal Law does not work in practice, and has many problems in implementation which are still unresolved. In this regard, we consider the main problems which are created in the work of the law in practice.

Authors agree with the opinion of the majority of the leading energy audit experts, who state that the information which is written in legal document, does not work in real market conditions. For example, until this day, the form and purpose of the energy passport are unclear. In addition, there are no clear requirements for the formalization of energy passport. No one knows what should be in the energy performance certificate, what institution must approve it. Today the Department of Energy has received a quarter of all formed energy certificates $[4 ; 6 ; 27]$.

In the current market conditions in our country there are more than two thousand energy auditing organizations that appeared at the time of the popularization of this theme. However, only hundreds of existing energy auditing organizations match to the selfregulatory organization. The law does not prescribe clear rules of the audit, but only puts certain requirements and terms under which managers are required to make energy certificate. As a result, due to the lack of clear guidelines for energy audit, the experts study the potential of energy efficiency companies, according to the "old" forms that were developed in 2000 with the enactment of subprograms "Energy supply saving in housing and utilities services", "Energy efficiency in energy-intensive industries ". It is only in rare cases, the analysis of the energy efficiency of the investigated companies is conducted competently and economically correct, and only because of giving the attention to the process [4; 5]. Thus, there is nothing about the development and implementation of specific measures for energy saving. In turn, the state does not finance the implementation of this law in practice.

Today, only a few regions and cities of our country can boast of a full-scale energy survey of the majority of housing and utilities services, industry enterprises and summarize its arrangement. Novosibirsk, Kazan, Tyumen, Kaliningrad, Tula, Perm, Penza - these are a few of the city, where there is the large-scale movement of the energy audit.

For example, today the Tyumen region is the leading region for realization of energy audits in the enterprises of housing and utilities sector and industry. In the Tyumen region a state contract is signed to conduct the energy surveys of state property objects. The contractor of the energy surveys is the company "Tyumenenergo". Currently the energy audit is conducted in the majority of state property objects, the results of which is developed set of measures for energy efficiency. In general, in the Tyumen region energy survey was conducted in 221 enterprises, so energy passports have been issued and registered in the Ministry of Energy of Russia. This is a rather high number, considering that there is a little more than 300 energy passports are registered in all the country. $[4 ; 5 ; 18]$.

It should also be noted that a few years before the enactment of law of energy saving, Tyumen region governance decided to use only modern technologies in carrying out all kinds of work in the construction of residential, industrial and other projects financed from the regional budget. As a result, since 2005 the number of accidents, malfunctions of network engineering through the use of modern energy-efficient technologies decreased by $40 \%$. Most of the buildings used by state and local authorities, are equipped with modern energy 
metering devices. Also, more than $50 \%$ of the housing stock of the Tyumen region is equipped with modern energy metering devices. [4; 6] Tyumen region is a prime example of the Russian region, understanding the significance and the importance of practical implementation of energy saving measures in housing and utilities sector and industry in order to further effective social and economic development of the region.

Another problem, according to experienced professionals' opinion in the sphere of energy audit, no less important is the fact that it is practically impossible to choose a competent auditor. Now more than two hundred energy auditing companies, which are relevant to SRO, function in the Russian market of energy auditing services. However, not all can have competent professionals. The problem is that the duration of the standard training courses of the energy audits basics is only seventy-two hours. But it is impossible to teach energy audit to specialist during this time. As a result, in Russia and its regions, less than one hundred energy auditing companies can offer professional services.

The next problem, which is noted by experts in the sphere of energy audit, is that there is no uniform methodology in Russia for energy audit in the enterprises of housing and utilities sector and industry, in which the clear specified algorithm of the energy enterprise survey would be noted. There is no methodology, which is a benchmark for comparing the energy efficiency results of the analysis of the investigated companies. However, we must remember that the energy survey will not give anything if there is no investment in energy-saving technologies for housing and utilities sector and industry $[4 ; 6]$. It is necessary to borrow the experience from foreign companies which offer their modern energysaving technologies and a clear methodology for conducting energy audits of the enterprises of all economic sectors, including enterprises of housing and utilities sector and industry $[7 ; 8 ; 10 ; 16 ; 20 ; 22 ; 24 ; 25$; 26].

We agree with the opinion of leading experts of energy audit that the subprogram "Energy supply saving in housing and utilities services", "Energy saving in energy-intensive industries," of the federal target program "Energy saving of Russia" has no relation with energy efficiency, because energy passports do not show the energy efficiency of the investigated companies and are only a simple inventory of energy equipment, buildings and structures.

It is important to mention that the experience of foreign countries proves that an energy audit within the energy-saving of housing and utilities services, industry and other sectors of the economy as a complex process needs the support of the state in our country. For example, in Finland the general direction of work in energy audit come from the Ministry of employment and economy of Finland. State center of economy, environment and transport offers subsidies to enterprises at the end of the work when the auditor has made the report and checked the quality of work with customer.
There are different models of the audit for each sphere of the client's company. The energy audit placed in the hands of business and SRO in Russia, but in Finland the state is interested in the results of the energy audit, because it allocates the funds to the project expertise. In addition, the Finnish auditors submit reports of energy audit, but in Russia - energy passports [4; 12; 16; 27].

The experience of Finland proves that the energy audit is a comprehensive approach to the analysis of a company, it is not only a solution of a technical problems, but also the economic problems, and problems of production development based on the implementation of specialized technologies, on the saving of the environment - the reducing of emissions and the negative impact on it. For Russia, the Finnish experience can be valuable because they have comparing data of the energy saving potential, substantiated theoretically by energy auditors in the technical report, and the actual energy saving potential, realized over the years in their country. The accuracy of theoretical predictions of the Finnish "energy auditors" is about 70 percent $[4 ; 12 ; 26]$.

Currently, the energy audit is provided by law, and formally its official status is confirmed. In practice, the term "energy audit" exists only in the law, its real functions are in formalities and uncertainties. Experts say that there is the need for new ideas, new rules, new decision-makers, and all this is not possible to approve by only one law.

Thus, there are problems in the implementation of the Federal Law №261-FZ ""About energy saving and energy efficiency increase and about changes in certain legislative acts of the Russian Federation" and the subprogram "Energy supply saving in housing and utilities services", "Energy efficiency in energy-intensive industries" on practice:

- the lack of clear rules and the absence of any budget for the implementation of the directions envisaged by the law;

- the lack of a single uniform of energy passport, the lack of clear requirements for its registration;

- the lack of competent professionals in the market of energy auditing services who are able to identify the reserves for possible savings of energy resources;

- there is no single clear methodology for energy audit or energy surveys of the enterprises in the utilities and industrial complex in the federal and regional level;

- the lack of investment projects to develop energysaving technologies for the enterprises of the utilities sphere and also for the enterprises of housing and utilities services and industry;

- the lack of regional services, centers for the organization and implementation of an energy audit in the enterprises of housing and utilities services and industry of various management levels;

However, as we have already noted above there are a lot of difficulties, related with the release of the $261 \mathrm{st}$ Federal Law "About energy efficiency and energy saving", but not all of them may be provided by law. 


\section{The main ways to solve these problems}

In our country, the attitude to the use of energy resources should be called wasteful, and it is rather a tradition than a temporary situation. The energy saving, unfortunately, is presented for us as a requirement of regulatory authorities. While the bases of careful attitude to electricity are laid in childhood abroad.

We agree with the Alexander Kuschinski, the head of the Centre of energy saving and energy efficiency increase of the Leningrad Region that we have to live ten years else to change the consciousness of citizens and the attitude to the concept of "economical consumption of resources." In the meantime, our mentality forces us to act very differently, even if the law is traditionally called upon to limit the rights.

According to General Director of NP "Soyuzpetrostroy-Energy Audit", the Candidate of technical science, Jakov Abugov, it is advisable to create a federal and regional (at the level of governors) coordination centers for improving the system of organization of the energy audit and energy saving. They should include the representatives of executive and legislative power, energy-governmental organizations, SROs, the various political parties. It is also necessary to strengthen the explanatory work among the population of energy saving through radio and television.

Thus, having considered many opinions, recommendations of leading economists and experts of energy audit, we have formulated the main directions to improve the effectiveness of the program realization of energy efficiency in the regional enterprises of housing and utilities sector and industry in practice:

- the creation of the federal and regional coordinate centers, organizing the work of complex energy survey of enterprises in utilities sector and industry, the results of which help to create priority courses of energy saving and their implementation;

- the development of a single methodology for energy audit at the federal level, as well as clear methodology of energy audits, energy-saving technologies, different models of the audit;

- the development of a single form of energy passport at the federal level (Ministry of Energy), as well as the establishment of clear requirements for its registration;

- the financial support from the state to conduct an energy audit in the regional enterprises of housing and utilities services and industry;

- the re-certification of the experts of energy auditing companies in according to their competence for the services provided by the energy audits of enterprises in the utilities

- the modification of the licensing criteria (more rigid) of the energy auditing companies providing services for energy survey of the regional enterprises of housing and utilities sector and industry;

- the public, private projects investment to develop energy-saving technologies in the enterprises in the utilities sector and in the enterprises of housing and utilities services and industry;

the change of the attitude in the need for energysaving measures of regional managers of public utilities sector, industry and the general public, by strengthening advocacy on energy efficiency by means of radio, television and the media.

\section{Conclusion}

Thus, in order to achieve good results, it is necessary to involve the professionals of all sectors of the economy, all producers and consumers of various fuel-energy resources. For successful implementation it is the need for concernment and involvement of all the participants of the events, among which there should be the executive authorities and local self-government of each city and region of Russia. Only when the maximum mobilization of used resources and the optimal return of energy saving policy subjects the thermal characteristics may increase in housing and utilities sector and industry, the equipment of accounting means, automatic control of production processes and the use of fuel-energy resources may improve and also control of energy consumption may be realized more efficiently as possible. However, as ordinary citizens, as well as all services and authorities, should remember that natural energy resources are finite and non-renewable.

\section{References}

1. State program "Energy saving and energy efficiency increase until 2020", approved by the Government RU from 27 December 2010 vol. 2446-p. http://www.consultant.ru.

2. N. Borisova, A. Borisov, Economy and business, 49, 728 (2014)

3. N. Borisova, A. Borisov, and E.Viprickaya, Economy and business, 12-3, 412 (2015)

4. V. Bushuev, Energy policy 1, 3 (2014)

5. N. Borisova., A. Borisov, and A. Taranova Construction Economics 39, 66 (2016)

6. N Borisova, A. Borisov, Actual problems of the introduction of energy efficient technologies in the construction and engineering of urban farming systems: Proceedings of the II International Scientific and Practical Conference, 13 (2015)

7. R. Simanjuntak, P. Dupuis, L. Canale, N. Sinisuka, and G. Zissis, IEEE Industry Application Society Annual Meeting, (2014)

8. X. Zhao, H. Li, L. Wu, \& Y. Qi, Energy Policy, 66, 170 (2014)

9. Y. Kim, A. Aravkin, H. Fei, A. Zondervan, and M. Wolf, IBM Journal of Research and Development, 60(1) (2016)

10. V. Blass, C. Corbett, M. Delmas, and S. Muthulingam, Energy, 65, 560 (2014) 
11. A. Sclafani, ASME 2010 4th International Conference on Energy Sustainability, 1 (2010).

12. L. Okkonen, and N. Suhonen, Energy Policy, 38, 3443 (2010)

13. T. Fleiter, J. Schleich, and P. Ravivanpong, Energy Policy, 51, 863 (2012)

14. S. G.Al-Ghamdi, and M.M. Bilec, Environmental Science \& Technology, 49, 4048 (2015)

15. P. Sun, and P. Nie, Renewable Energy, 74, 255 (2015)

16. M. Marques, and R. Neves-Silva, Journal of Cleaner Production, 88, 105 (2015)

17. Y.P. Gusev, Thermal Engineering, 62(3), 160 (2015)

18. V.U. Baldin, N.I. Danilov, and G.I. Khudyakova, Energy Production and Management in the 21st Century, (2014).

19. W.Y. Saman, L. Mudge, D. Whaley, and E. Halawa, Sustainability in Energy and Buildings Smart Innovation, Systems and Technologies, 247 (2012).
20. A. Al-Mofleh, S. Taib, and H. Al-Gulman, 2008 5th International Symposium on Mechatronics and Its Applications, (2008)

21. W. Zhang, S. Liu, N. Li, H. Xie, and X. Li, Renewable and Sustainable Energy Reviews, 49, 395 (2015)

22. A. G. Engelen, \& J. S. Collins, 2010 43rd Hawaii International Conference on System Sciences, (2010).

23. M. Abdel-Wahab, and D. Ali, International Journal of Green Energy, 10(2), 137 (2013).

24. A. Mansikkasalo, and P. Soderholm, 2012 9th International Conference on the European Energy Market, (2012)

25. M.O. Melo, L.B. Silva, A.S. Coutinho, V. Sousa, and N. Perazzo, Energy and Buildings, 47, 35 (2012)

26. O. Maksimchuk, and T. Pershina, Sociology of City, 2, 104 (2016)

27. O. Maksimchuk, T. Pershina, G. Golikova, N. Borisova, and S. Ivashova, The concept of energy saving management in housing and communal services: a systematic approach, 284 (2015) 